\title{
Comparative Studies on Cotton Seed Germinability with Tetrazolium Viability Test and $X$-ray Contrast Methods
}

\author{
Young-Wang Na*, Sang-In Shim**, Jung-Sung Chung**, Il-Rae Rho**, and Seok-Hyeon Kim**† \\ *Research Policy Bureau, Rural Development Administration, Suweon 441-707, Korea \\ **Research Institute of Life Science, Gyeongsang National University, Chinju 660-701, Korea
}

\begin{abstract}
Seed viability testing provides valuable information for assessing seed lot germinability. However, most testing methods require destruction of seed prior to test. Because the dissected seeds for viability test cannot be used further evaluation, the nondestructively X-ray photography technique that can be applied for the evaluation of seed quality has been developed. In order to know the validity and accuracy of X-ray photography technique in seed evaluation test that conducted to remove the abnormal seed from a seed lot, we have compared the results from tetrazolium viability test, germination test and X-ray contrast method in cotton. Metallic salts treatment increased the efficiency of X-ray photographic method by enhancing the penetration of X-ray in abnormal or damaged seeds rather than normal seeds that have strong and well-organized tissues in seed. Cotton seeds presoaked for $16 \mathrm{hr}$ in distilled water followed by soaking into metallic salt solution $(5 \% \mathrm{NaI}$ in water) for $60 \mathrm{~min}$ were easily classified seeds into dead seed and viable seed based on the radiography images obtained by X-ray radiation. We concluded that soft X-ray photography was reliable to find out the various defective characters due to heat and mechanical damage of seeds.
\end{abstract}

Keywords : cotton, x-ray analysis, tetrazolium viability test, seed germination, non-destructive, seed viability

Seed viability test has been used by not only standard germination test (SGT) but also various methods including tetrazolium viability test, enzyme assays, staining technique, conductivity test, cutting test, and excised embryo technique. $\mathrm{X}$-ray analysis, a newly developed method, is applying to evaluate the seed viability by imaging internal structure. The most beneficial advantage of X-rays in seed testing is to obtain a quick indication of abnormality or mechanical damage that might impair germination capacity. Additionally, due to the non-destructive property, seeds exposed to X-ray can be reused without deterioration after testing. Tetrazolium viability (TZ) test is a valuable for estimating seed viability and determining reasons that cause poor germination. But TZ test can not be applied in case of deep dormant seeds and some types of abnormal seedlings that can not be detected by TZ tests. For this reason, both $\mathrm{TZ}$ and germination tests should be conducted simultaneously in most seed inspection procedure.

Since the application of X-ray radiography to determine seed viability was conducted by Simak and Gustafsson (1953), Smith and Grabe (1985) extended its applicability as a rapid method for determining the germinability of corn seed through the barium chloride impregnation technique (X-ray contrast method). This method is based on the principle that the salts of heavy metals enter the dead tissues of the seed by diffusion, whereas the living cells prevent their entry. The germination percentage of the viable seeds (un-impregnated or impregnated only to a small part) then be calculated on the basis of the embryo and endosperm behavior. This X-ray contrast method was further applied to several kinds of agricultural and horticultural seed by Swaminathan and Kamra (1961). X-ray test has been used for evaluation of seed quality (Kamra, 1964 and 1976; Simak, 1970; Simak and Gustaffson, 1953), detection of disease-infected seed (Kamra, 1976; Yates, 1974), clarification of reasons for delayed germination (Devillez, 1971) and reasonable expectation of seed quality (Simak and Alfjorden, 1973). The most beneficial use of the X-ray test is to detect seed quality. This test can be

${ }^{\dagger}$ Corresponding author: (Phone) +82-55-772-1871 (E-mail) seedvigor@hotmail.com

$<$ Received 2 April, 2014; Accepted 26 May, 2014> 
also applied to reveal the inner structure of seed and the structural deficiencies during seed development. Using X-ray analysis, Argerich and Bradford (1989) reported the occurrence of free space between embryo and endosperm in primed tomato seed after drying. In the study of Chen and Sun (1991), they showed that the non-destructive method with X-ray was suitable for evaluating the efficiency of seed priming as well as seed quality associated with mass density variation. As shown in the result of Van der Burg et al. (1994), X-ray photography method can be applied to know the morphological properties of embryo and seedling. The method also has been used for knowing physical changes during germination (Van der Burg et al., 1994) and other seed characters (Kim et al., 1982)

In the present paper, we have compared the two rapid methods: the tetrazolium test and the X-ray contrast test (Simak, 1957; Swaminathan and Kamra, 1961) with standard germination test for knowing the germinability of cotton seed. Seed viability are directly evaluated by germination test after estimation of damaged (mechanical, heating), deteriorated seeds by X-ray contrast test. The technique was then compared with measurements of tetrazolium viability as well as with germination test, the latter two tests are officially accepted methods for evaluating viability of seeds (ISTA, 2003; Kim et al., 1987 and 1994 ; Smith and Grabe, 1985). In this study, a quantitative high contrast X-ray radiographic technique was developed to measure various changes in cotton seeds that the viability was artificially controlled.

\section{MATERIALS AND METHODS}

\section{Seed samples}

The cotton (Gossypium hirsutum L.) seed was harvested in Sanchong-gun, Gyeongnam, Korea. The collected seed was stored at $5^{\circ} \mathrm{C}$ until use. Seeds were classified into following groups depending on seed condition.

- Normal (strong): Seeds collected properly matured open boll.

- Abnormal (weak): Seeds collected from the immature boll

- Abnormal (heat damaged): Keep at $60 \sim 70^{\circ} \mathrm{C}$ for 48 hours.

- Abnormal (mechanical damaged) : Seeds were damaged by using ball mill at $25 \mathrm{rpm}$ for $10 \mathrm{sec}$.
Seeds with lint were stirred in concentrated sulfuric acid for $20 \mathrm{sec}$ then dried after rinse with tap water. The seeds were subjected to heat and mechanical damage treatment after removal of lint.

\section{Metallic salts treatment}

Sodium iodide (NaI) was used to prepare contrast solution. One hundred seeds were presoaked in distilled water for $16 \mathrm{hr}$, and then transferred into 5\% NaI and held for 60 min. The seeds were subsequently subjected to X-ray radiography. The toxicity of the contrast agents (NaI) was determined through germination tests and measurements of roots and shoot lengths.

\section{X-ray contrast test}

The pretreated seeds were loaded on white paper sheet and placed $20 \mathrm{~cm}$ apart from X-ray source window then $\mathrm{X}$-ray was radiated by a Soft X-ray machine (SOFTEX TV-25-1) which had a pre-set amperage of $3 \mathrm{~mA}$. The radiation intensity and time of X-ray radiation for discriminating internal damages or defects of cotton seed was $17 \mathrm{kV}$ and $10 \mathrm{sec}$, respectively. The radiography was developed by using sensitive X-ray film [FUJI X-ray FILM $12 \times 16.5 \mathrm{cmJx}(4 \times 6)]$. After exposure, the film was immediately processed in the dark.

\section{Standard germination test}

According to the "International Rules for Seed Testing" (ISTA, 2007), 100 seeds wrapped with rolled paper towel were placed at $25^{\circ} \mathrm{C}$ for 12 days. The germination test was conducted with four replications. Seed showing a part of radical was regarded as germinated seed.

\section{Tetrazolium viability test}

Tetrazolium viability test was conducted according to "Working Sheets on Tetrazolium Testing" (ISTA, 2003). Samples were soaked in distilled water for up to 18 hours at $25^{\circ} \mathrm{C}$. Seeds were stained for 3 hours at $35^{\circ} \mathrm{C}$ in the $0.5 \%$ tetrazolium solution. Seed coat of each seed was removed to expose radicle tip for evaluation.

\section{Statistical analysis}

A correlation analysis was performed between X-ray 
analysis value, TZ viability and percent of germination with MSTATC package (1993).

\section{RESULTS AND DISCUSSION}

\section{Development of a high contrast $\mathrm{X}$-ray radiographic technique}

Cotton seed immersed into $5 \%$ solution of sodium iodide (NaI) for 60 minutes was suitable for X-ray radiography. However, this high solution was not suitable for germination since this treatment was toxic to the germinating seeds (data not shown). Moreover, increasing in the amount of impregnation is greater by this treatment. But one hour soaking in $5 \%$ sodium iodide solution of the presoaked seed (16 hours in water) proved to be optimal in creating a better contrast between impregnated (dead) and un-impregnated (viable) seeds (Fig. 1). Difference in germination behavior was observed in cotton seed when exposed to find the difference of a lower $5 \%$ concentration and a high $25 \%$.
A light diffuse-type was observed in the seed samples that have reduced-viability under salts of sodium iodide. Heavy impregnation was shown in the sample of dead seed, on the other hands, slight in the sample with reducedvitality seed and no impregnation in the fresh seed sample were observed. Fig. 1 showed distinct difference between the impregnation of the samples of fresh and dead seed.

\section{Comparison of the X-ray contrast method with standard germination test and tetrazolium viability test}

The values of germinability according to the X-ray contrast method with $\mathrm{TZ}$ viability test and the grouping given above are summarized in Table 1. Germination percentage was calculated on the basis of the Table 1. In general, these results obtained from X-ray test showed greater values than those from TZ test and SGT. It was supposed that difference was come from dormancy seed in the same seed lot.

Correlation analysis result from $\mathrm{TZ}$ viability test and
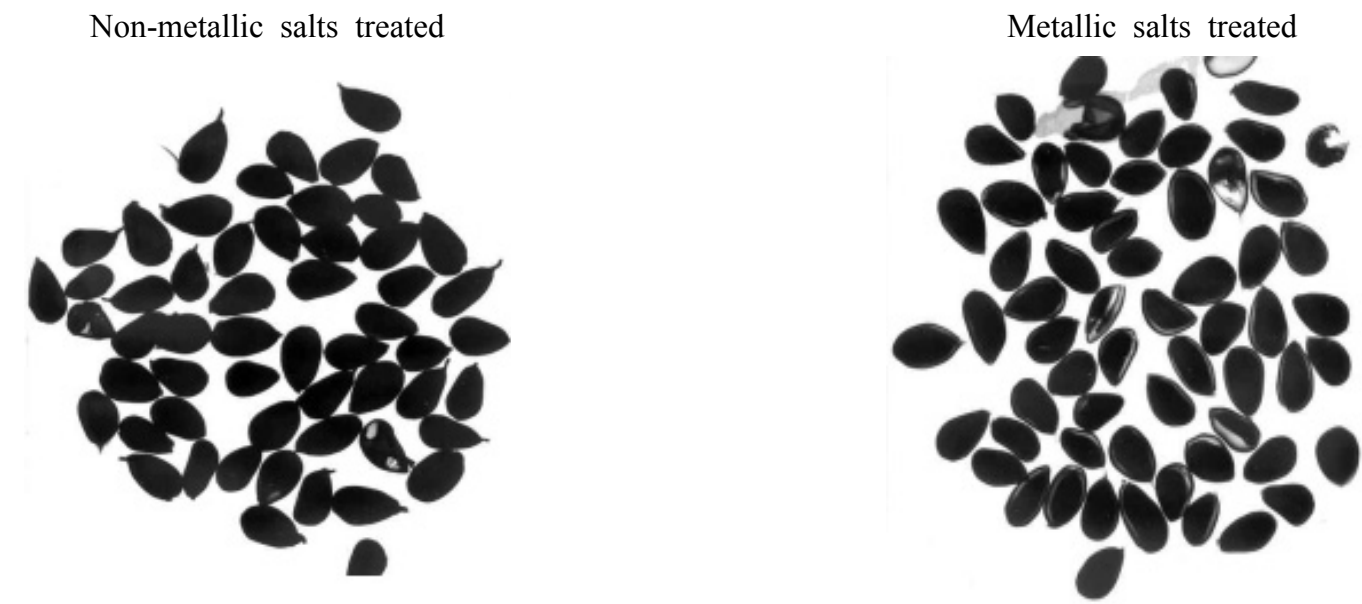

Fig. 1. X-ray radiograph for seeds of cotton treated with sodium iodide. The impregnated (light in color) and un-impregnated ones (dark in color) are discriminated by color intensity.

Table 1. Viability and germinability of $\mathrm{TZ}$ and standard germination test before and after X-ray radiation in cotton seed.

\begin{tabular}{lccc}
\hline \hline Seed samples & $\begin{array}{c}\text { TZ viability after expose } \\
\text { X-ray }\end{array}$ & $\begin{array}{c}\text { Percent of germination } \\
\text { after expose X-ray }\end{array}$ & $\begin{array}{c}\text { Percent of germination } \\
\text { before X-ray radiation }\end{array}$ \\
\hline Normal (strong) & $82 \pm 2.2^{\dagger}$ & $77 \pm 2.9$ & $85 \pm 2.0$ \\
Abnormal (weak) & $17 \pm 1.5$ & $11 \pm 0.9$ & $20 \pm 1.8$ \\
Abnormal (heating damage) & $83 \pm 1.5$ & $72 \pm 1.3$ & $86 \pm 2.0$ \\
Abnormal (mechanical damage) & $73 \pm 3.9$ & $72 \pm 1.9$ & $70 \pm 4.0$ \\
\hline
\end{tabular}

\footnotetext{
${ }^{\dagger}$ : means \pm standard error.
} 
Table 2. Correlation coefficients between $T Z$ viability after $X$-ray radiation, percent of germination after X-ray radiation, and predicted germination percentage by X-ray test in cotton seeds.

\begin{tabular}{lccc}
\hline \hline & & \multicolumn{2}{c}{ Correlation coefficients } \\
\cline { 3 - 4 } Normal (strong) & X-ray & TZ viability & Percent of germination \\
& TZ viability & $-0.901^{*}$ & $0.974^{* *}$ \\
& & & -0.841 \\
Abnormal (weak) & X-ray & -0.723 & -0.764 \\
& TZ viability & & 0.138 \\
Abnormal (heating damage) & X-ray & & -0.672 \\
& TZ viability & 0.597 & $0.923^{*}$ \\
Abnormal (mechanical damage) & X-ray & & -0.331 \\
& TZ viability & 0.361 & 0.087 \\
\hline
\end{tabular}

$*$, ** indicate significance at the $5 \%$ and $1 \%$ levels respectively.

\begin{tabular}{llccc}
\hline \hline \multirow{2}{*}{ Seed samples } & \multicolumn{2}{c}{ Standard germination test } & \multicolumn{2}{c}{ Tetrazolium test } \\
\cline { 2 - 4 } & Before & After & Before & After \\
\hline
\end{tabular}

Normal

(strong)
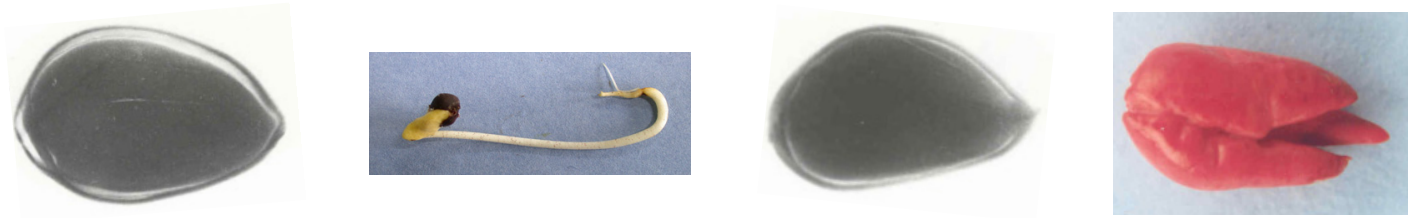

Abnormal

(weak)
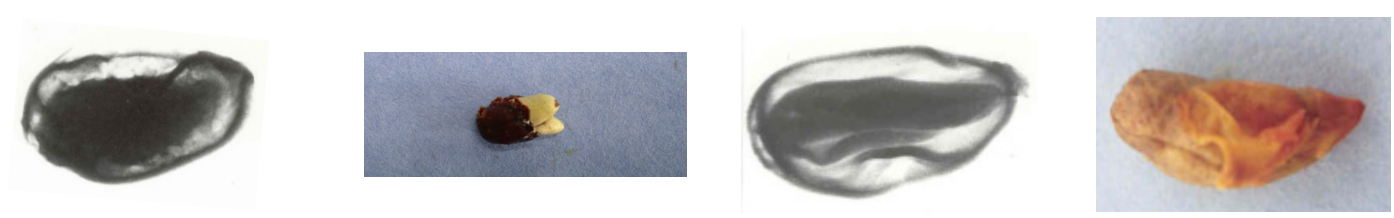

Abnormal

(heating damage)
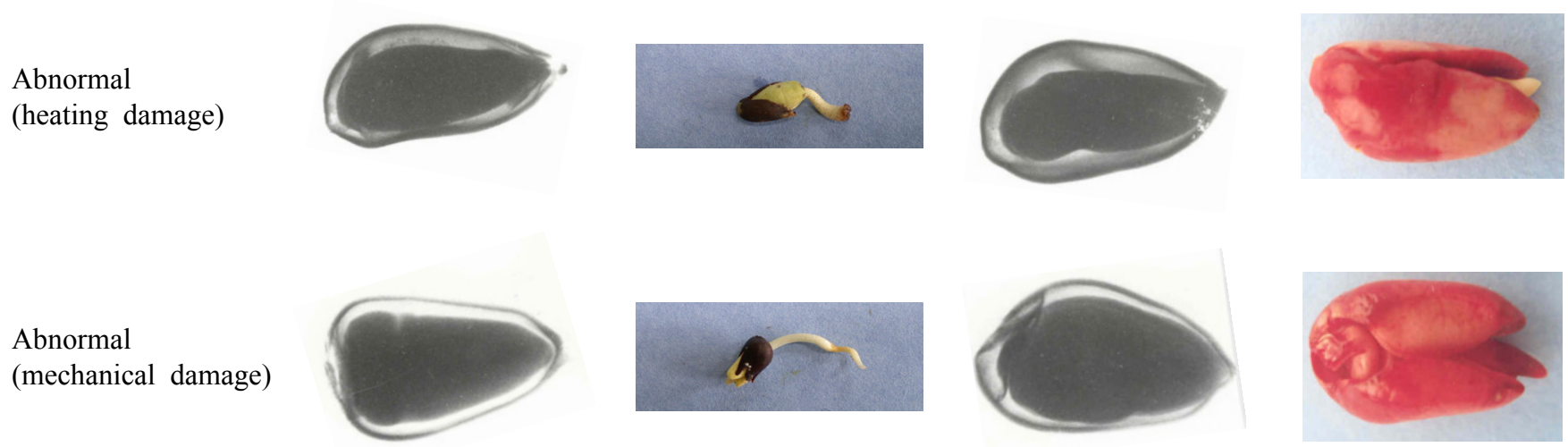

Fig. 2. Germination of normal, weak, heat and mechanical damage seeds. 
SGT for the cotton seed subjected to X-ray radiation was in Table 2. X-ray test was effective to predict the emergence of healthy seedling from cotton seed showing the higher correlation coefficient $\left(0.974^{*}\right)$ in normal seed. TZ test also was consistent with the result of X-ray test results $(-0.901 *)$. However, the X-ray test did not predicted germinability well in unhealthy (weak), heat-damaged or mechanically damaged seeds. In the case of heat-damaged seeds, however, the germinability was predicted well $(0.923 *)$ by X-ray test. Internal structure of healthy seed that showed normal elongation of plumule and radical was clear and well-organized (Fig. 2). In the photos of Fig 2, the germinated seeds after X-ray radiation (left) and TZ test of seeds after X-ray radiation reflect that X-ray radiation did not affect adversely to the seed germination and viability. The result from $\mathrm{TZ}$ test was similar with stained pattern of tetrazolium viability test.

In weak seeds, X-ray results show the difference in the proportion of empty space in internal structure between normal and abnormal seeds. In the germination test, abnormal seed did not show any emergence of radicle. The seed has large ( $>$ half) empty space did not germinate after $\mathrm{X}$-ray radiation. TZ test shows the same result. Abnormal seed shows only brown color in TZ test. The dead tissues were localized within vital embryo or cotyledons. Any impregnation (partial or entire) was not observed in the embryo or cotyledons of weak seeds.

Heat-damaged seed showed lots of empty tissue by $\mathrm{X}$-ray contrast test and did not germinated in standard germination test. The changes of heat-damaged seeds were the structure modification such as shrinkage of entire or a part of seed. These changes resulted in the lowered longevity. Although it has been known viable seed can be stained in both embryo and endosperm (Bulant, 1959), the radical from cotton seed was not completely stained in $\mathrm{TZ}$ test suggesting the radical originated from embryo was more easily damaged by heat than endosperm. However, Lakon (1950) reported that viability loss of seed was commenced with necrosis of endosperm part.

X-ray test revealed that mechanically damaged seed had cracks in cotyledons. Seed germination was delayed by mechanical damage. Generally, the greatest reduction of seed vigor was observed in unhealthy (weak) seed, on the other hand, the mechanically damaged seed showed greatest change in seed vigor.

\section{ACKNOWLEDGEMENTS}

This paper is a tribute Mrs Cho hyunjung writes. Application is expressed to Dr. Tak, wooseek for his advice on radiography and for use of X-ray equipment at the Forest Genetics Institute Seed Laboratory in Suweon, Korea.

\section{REFERENCES}

Argerich, C. A. and K. J. Bradford. 1989. The effects of priming and ageing on seed vigour in tomato. J. Exp. Botany 40 : 599-607.

Bulant, H. 1959. Test Instruction according to the Lakon topographical tetrazolium method for determine germination capacity of tree seeds. Proc. ISTA. 22(1) : 1-4.

Chen. P. and Z. Sun. 1991. A review of non-destructive methods for quality evaluation and sorting of agricultural products. J. Agri. Engin. Res. 49 : 85-98.

Devillez, F. 1971. Quelque aspects morphologique de la germination chez Pseudotsuga menziesii (Mirb.) Franco var. Menziesii. La Cellule 69:27-44.

ISTA. 2003. ISTA Working Sheets on Tetrazolium Testing I. International Seed Testing Association.

ISTA. 2007. International Rules for Seed Testing. Edition 2007. International Seed Testing Association.

Kamra, S. K. 1964. Determination of germinability of cucumber seed with X-ray contrast method. Proc. ISTA 29(3) : 519-534.

Kamra, S. K. 1976. Use of X-ray radiography for studying seed quality in tropical forestry. Studia Forest. Suecica 131 : $1-34$.

Kim, O. R., C. S. Kim, and J. S. Kim. 1982. Use of Soft X-ray photography for studying seed quality in grass and tree. J. Korean For. 55 : 47-54.

Kim, S. H., L. O. Copeland, and R. Baalbaki. 1987. The use of multiple tests in predicting the vigor of soybean seeds. Korean J. Crop Sci. 32 : 268-276.

Kim, S. H., Z. R. Choe, J. H. Kang, L. O. Copeland, and S. G. Elias. 1994. Multiple seed vigour indices to predict field emergence and performance of barley. Seed Sci. \& Technol. 22 : 59-68.

Lakon, G. 1950. Die Fsetstellung der keim fahigkeit der koniferensamen nach dem topographischen TetrazoliumVerfahren. Saatgut-Wirtschaft 4 : 83-87.

MSTATC. 1993. Michigan State University MSTAT Development Team. MSTAT User's Guide. Michigan State University, 
MI, USA.

Simak, M. and A. Gustanfsson. 1953. X-ray photography and sensitivity in forest tree species. Hereditas $39: 458-468$.

Simak, M. 1957. The X-ray contrast method for seed testing: Scots pine-Pinus silvestris. Medd. F. Stat. Skogsforsk. Inst. 47(4) : 1-22.

Simak, M. 1970. New used of x-ray method for the analysis of forest seed. Proc. IUFRO Sect. 22, Working Group Meeting on Sexual Reproduction. Varparanta, Finland. (Research Note No. 23 : 1-12. Dept. of Reforestion, Royal College of Forestry, Stockholm).

Simak, M. and G. Alfjorden. 1973. Kottfore komst och frovarde hos gran och tall insamlingssasongen 1973-74 : Skogen, 60.
Smith, A. J. and D. F. Grabe. 1985. Radiographic density measurements for determination of viability and vigor in corn (Zea may L.) seeds. Seed Sci. \& Technol. 13 : 759-768.

Swaminathan, M. S. and S. K. Kamra. 1961. X-ray analysis of the anatomy and viability of seeds of some economic plants. Indian J. Genetics \& Plant Breeding 21 : 129-135.

Van der Burg, W. J., J. W. Aartse, R. A. Van Zwol, H. Jalink, and R. J. Bino. 1994. Prediction of tomato (Lycopersicon esculentum Mill.) seedling morphology by X-ray analysis of seeds. J. Amer. Soc. Hort. Sci. 119(2) : 258-263.

Yates, H. O. 1974. Radiography for detection and study of insects in plant seeds. Proc. Seed X-ray Symposium, Macon, Ga, USA 65-78. 